\title{
Concept Mapping and Mind Mapping to Lift the Thinking Skills of Chemical Engineering Students
}

\author{
http://dx.doi.org/10.3991/ijep.v4i5.3538 \\ I.M. João ${ }^{1,2}$ and J.M. Silva ${ }^{1,2}$ \\ ${ }^{1}$ Instituto Superior de Engenharia de Lisboa (ISEL), Lisboa, Portugal \\ ${ }^{2}$ Universidade de Lisboa, Lisboa, Portugal
}

\begin{abstract}
Chemical product and process design teaching is facing challenges due to the major changes occurred in the last decades in the chemical industry. The emergence of products as a focus for chemical engineers implies changes in what chemical engineers do. It is important to prepare students for the more diverse, flexible roles they are expected to perform in industry and nowadays it is requisite that chemical engineers participate in the whole process from conception to manufacture. This paper addresses the activity of ideas generation, a very important step in product and process design procedure, and explores the role of concept maps and mind maps along with the discussion of the main features of the methods used to map and structure the ideas. The main goal of this paper is to present the methods within the context of product and process design teaching and learning showing the potentialities of the methods as graphical representations, in the ideas generation step in order to allow free-flowing thoughts. An illustration of the maps performed by chemical and biological engineering master students within the product and process design curricular unit is presented along with the main conclusions. This type of maps is promising in order to allow chemical and biological engineering students gradually lift their skills.
\end{abstract}

Index Terms - chemical product design, concept mapping, creative thinking, mind mapping, process design.

\section{INTRODUCTION}

In an increasingly dynamic market, the firms' aptitude to continuously identify the needs that the products must fulfil and create products that are able to meet customers' needs is essential in order to ensure business competitiveness.

The Chemical Process industries (CPIs) experienced in recent years a great evolution due to the important social, techno-economic and environmental concerns they faced in a local and global scale and so the requirements associated with the skills and technical knowledge of the chemical engineers also experienced a great evolution. According to Cussler and Wei [1] the world of chemical engineering has changed so radically that engineers have to reinvent themselves in order to ensure continued prosperity.

One of the main changes observed in chemical industry in the last decades concerns its evolution from commodity chemicals where the price is the critical criterion in the purchasing decision to more sophisticated products where the major concerns is around performance and quality [2].
Actually chemical engineers deal with a wide range of products beyond commodity chemicals, namely specialty chemicals, devices for chemical change and formulated products, this last classically classified to cover a large body of industrial sectors (e.g. paints, cosmetics, inks, pharmaceutical, personal care, household, food). Since many of the chemical products of today and tomorrow do not have much in common with those of twenty years ago, the portfolio of skills and technical knowledge required by chemical engineers has also been changing rapidly [3].

A major trend in the field of CPIs that is worth to mention is that companies were used originally to develop their identity around chemical concepts whereas today the paradigm has changed with product properties acting as the major criterion of the industrial strategy of business units. It means that CPIs are no longer subdivided according to what chemicals they produce but rather by the enduse properties of their products. The trend in CPIs is to provide the customers not only with a chemical in the strictest sense of the term but also with a product [4]. The emergence of products as a focus for chemical engineers implies changes in what chemical engineers do. Individual substances are no longer able to meet the ever-increasing demands of customers and so chemical engineers are required to develop tailored products to meet customers' expectations, the so-called end use properties.

This increased demand for product differentiation and customization is accompanied by the time to market pressure and the need for rapid product design and so companies must look for more efficient ways to integrate consumer's input into the product and process design procedure.

It is essential that chemical engineers be involved in teams of marketers, synthetic chemists and operations engineers among others in the joint effort of product and process design and participate in the whole process from conception to manufacture $[1,5]$. It is important to prepare students for the more diverse, flexible roles they are now expected to perform in industry, and so it is requisite that nowadays chemical engineers are involved in all of the main steps of the product design procedure (Fig. 1).

The very first step towards the production of a product is defining the product. In doing this customer needs and expectations need to be captured (e.g. the expectation that the product would last longer, be more environmental friendly, combines several attributes, among others). Based on customer needs and benchmarking the customer needs are translated into target specifications that repre- 
sent the hopes and aspirations of the team, and are established before the team knows what constraints the product technology will place on what can be achieved. The second step is the generation of ideas which objective consists in generating many different ideas or different product concepts with divergent thinking techniques leading to the creation of a flow of ideas without thinking how good or bad they are. The selection of ideas is the third step and seeks to thin down the idea set into a very small set of ideas, maybe one that will be taken forward for further development. The divergent thinking of step two is followed by convergent thinking in which the team selects the ideas deciding what to keep and how to proceed. Finally, in the last step the team decides how the product will be manufactured and the final specifications will be reached.

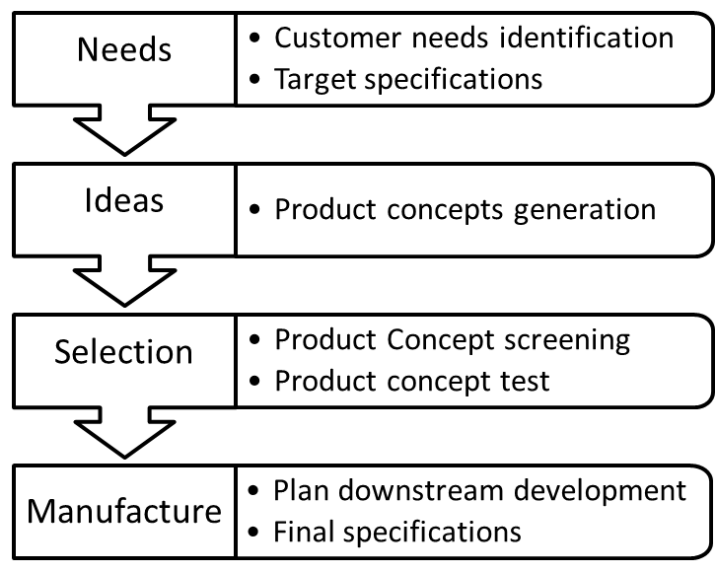

Figure 1. Main steps of the product design procedure

This is a major simplification of the chemical product design procedure consisting in a framework of tools whose aim is to provide faster and efficient design of innovative chemical products able to meet or even exceed customers' expectations.

In order to gain competitiveness in the 21 th century it is of utmost importance to cultivate skilled chemical engineers able to create and be taught to become innovative problem solvers.

It is important to provide chemical engineering students with methods and background to improve the output of their creative thinking in their profession. This paper addresses the activity of ideas generation, a very important step in product/process design procedure emphasizing the relevance of concept maps and mind maps to provide chemical engineering students the background to improve the creativity in the day-to-day work of a chemical engineer.

The paper is organized in five sections. Section II explores the role of creative thinking in education highlighting the relevance that creativity plays in the idea generation step of product design procedure. Section III presents two ideas mapping methods along with the different fields of study where the methods were developed along with the main characteristics of each method. Section IV presents an illustration of concept mapping and mind mapping produced by chemical engineering students. The case refers to the idea generation step. Finally section V presents the conclusions highlighting the potentialities of the maps in lifting the thinking skills of the chemical engineering students.

\section{The Role of Creative Thinking In Education}

Chemical product and process design is by no means of dough a creative exercise. The chemical engineer along with the development team must create new products using the tools he/she have been taught. Nevertheless, engineering students usually do not see their engineering training as requiring much creativity particularly in their first few years of college [6].

The special approaches to the development of creative thinking have never been known to achieve miracles but lifting the students' problem solving skills by a small amount can have an incalculable effect on innovation and competitiveness [7]. Creativity is one of the major education reforms in the world nowadays. All advanced countries pay more attention on the inspiration of student' creative thinking ability $[8,9]$.

There are many signs evidencing the growing strengths of the global economy particularly in Asia. The creativity plays its role in the development of Asian countries as we can see for instance that in Japan the National Council on Education Reform (NCER) has outlined the development of creativity as the most important objective of education for the 21th century [10]. Also, China has made rapid advances in areas such as education in the last years and creativity has become a priority since 2001 [11].

The use of creativity during the design should be considered as an integral part of the chemical product design [12]. However in the process of creative thinking the most important step is the idea generation indicating that creativity is an indispensable element. Creativity can be developed and stimulated through training and learning activities and creative thinking teaching practices can promote students' learning motivation and cultivate their thinking ability. Students need to understand that creative products are seldom produced without intent and effort and so multiple techniques are used to stimulate divergent thinking and to induce creativity $[13,14]$. Divergent thinking typically occurs in a spontaneous, free-flowing manner, such that many ideas are generated. One idea might lead to another idea without formal logic interfering and so many possible product or process concepts can be exploited in a short amount of time. Nevertheless, this does not mean that divergent thinking is synonymous with creativity or creative thinking. Certainly, as the type of thinking responsible for new ideas, divergent thinking is a necessary component of creativity. After all, a person must have novel ideas before develop a new product or a new solution to a problem. When the development of a novel idea is a person's goal, divergent thinking and creativity probably can be considered equivalent [15]. There is considerable evidence of various kinds to support the alleged relevance of divergent production for successful creative thinking $[16,17]$.

Most of the chemical engineering students are not natural creative thinkers, as most of us, and so some idea generation methods are required to change the usual thinking process and to stimulate creative thinking. Idea generation methods may be classified broadly into two categories intuitive and directed [18]. The intuitive methods intent to remove barriers to divergent thinking so that new connections and features in a product may be visualized. By removing these barriers, the environment of idea generation may be filled with conditions that promote creativity. Some methods of generating concepts are traditional 
brainstorming, brain writing, or some sequential methods like storyboarding or affinity method among others. The divergent thinking is an important facet of the creative thinking process. The creative process does not directly lead us to the best idea but encourages a variety of new ideas, new product concepts, and in the intuitive process of idea generation an idea is followed in several directions to lead to one or more new ideas, which in turn lead to still more ideas.

It is important to map the ideas, in order to organize and structure them and visual mapping allows complementing and enhancing the divergent thinking techniques as for example the visualization of the relationships among the brainstormed ideas. There are some mapping methods that might be of interest in chemical product and process design to be used as an effective visual documentation of concepts generated by the team members, which are responsible to the development of the target product. There are different types of mapping methods offering different frameworks for organizing the ideas and providing insight into the generated concepts. Maps are valuable learning tools helping to spread existing ideas, and to formulate new ones.

\section{ORIGIN AND CONSTRUCTION OF CONCEPT MAPS AND MIND MAPS}

An idea map is a visual representation of the ideas and their interconnections. The mapping of the ideas is a form of structuring and can be very useful for the product development team in order to better frame their ideas.

The ideas mapping offer a framework for the team to organize their ideas and also provide a better perception of the generated ideas allowing the construction of a shared mental model promoting the team learning behavior and leading to increased effectiveness [19].

The maps can have a powerful role in promoting group learning because they capture the groups' thinking efficiently and inclusively providing the team with a valuable insight of the generated ideas. The visualization is an important issue in the creative phase of design where ideas are explored by means of visual representation.

The methods illustrated in this paper are concept mapping and mind mapping and so it is important to understand the different fields of study where the methods were developed.

The concept mapping was mainly developed by Joseph Novak in the field of education and inspired by the work of the cognitive psychologist David Ausubel who first introduced his Assimilation Learning Theory in the 1960s [20]. According to Ausubel, the most important single factor influencing learning is what the learner already knows. Ausubel compares meaningful learning to rote learning, which refers to when a student simply memorizes information without relating that information to previously learned knowledge. As a result, new information was easily forgotten and not readily applied to problemsolving situations because it was not connected with concepts already learned. Ausubel believed that knowledge structures are organized hierarchically with more inclusive and general ideas comprising concepts that are more detailed. Concept mapping represents knowledge structures as hierarchies The meaning of each of the concepts could be defined on the basis of its relationships with other concepts. Thus concept mapping supports learners to activate meaningful learning processes by explicitly relating new information to what they already know. Doing so learners could modify or change completely the meaning of particular concepts.

Novak developed the concept mapping method and his research was mainly focused on educational studies, knowledge creation, and knowledge representation. He has developed a theory of education to guide research and instruction, first published in 1977 [21]. There are several studies concerning the use of concept maps mostly as graphical organizer and evaluation technique in teaching and also as learning aid to students organize their structural knowledge [22-24]. There are some examples in engineering disciplines such as mechanical, chemical, computer and electrical engineering where the concept maps were used as a learning tool [25-27].

The mind mapping method was popularized primarily by the British psychology author Tony Buzan in a BBC series hosted by Buzan and called "Use your head" [28]. Mind maps have a long history, dating back to the third century. Early thinkers and philosophers used graphic designs to diagram various concepts, words and ideas that related to a central thought. Mind maps are a visual method for recording thoughts and related ideas graphically. Buzan was inspired in the work of Korzybski general semantics and this lead to further studying psychology, neuropathology of the brain, semantics, neuro linguistics, and creative thinking [29]. Buzan uses popular assumptions about the cerebral hemispheres in order to promote the use of mind mapping over other forms of note making.

Buzan and Buzan [29] found that standard note taking is poor and does not take into consideration other tools that our mind makes available such as, visual pattern, color and image for example.

Mind mapping has been introduced as an explicit model of the associative way the human mind organizes information. The method has four main characteristics: the issue under evaluation is the central topic, main themes of the issue radiate from the central topic as branches, branches comprise a key image or key word printed on an associated line and topics of lesser importance are also represented as branches attached to higher level branches. The mind maps are based on radial hierarchies denoting relationships with the main central issue.

\section{A. Concept mapping}

The construction and use of concepts maps have been developed at Cornell University and worldwide use of this maps reported increasingly in the literature since the publication of "Learning how to learn" by Novak and Gowin [24] and also [30, 31]. A concept map is a graphical tool for organizing and representing knowledge. It includes "concepts" usually enclosed in circles or boxes of some type and relationships between concepts indicated by a connecting line linking two "concepts". The words on the line specify the relationship between two concepts and are referred to as linking words or linking phrases [32]. A concept is a label given to "an idea of a class of things" often but not necessary expressed by a single word. The linking words on the lines connecting concepts are important in order to form explicit propositional statements and so the relationships between concepts are known as "propositions". The concept map is hierarchical with the broadest, most comprehensive statements at the top of the hierarchy and the more specific statements at lower levels. 
A concept can be related to other concepts by multiple links. In order to create a concept map to generate and structure the ideas the development team can follow some steps:

1. Identify the general/broad idea.

2. Brainstorm on the general idea and list all the concepts and themes related to the topic. Keep the concepts as concise as possible. It can be helpful to write the concept labels on separate cards or small pieces of paper or post-its so that they can be moved around.

3. Identify the hierarchy of the concepts in the list from the broadest more general concept to the most specific.

4. Connect the concepts by lines. Label the lines with action or linking words. The linking words should define the relationship between the two concepts so that it reads as a true statement, or proposition. The connection creates meaning. When you can hold together a large number of related ideas, you can see the structure of meaning for a given subject area.

5. Construct the preliminary concept map.

6. Review the map and look for cross-links, links between the different domains of the map.

\section{B. Mind mapping}

A mind map consists of an imaginative way of register ideas and is an effective method of notes taking and useful in the generation of ideas by association [28,33]. The author argued that the normal linear methods of taking notes and recording ideas do not make efficient use of the brain and so he developed the mind map which is a dynamic way to record information. The mind map consists of a main idea summarized as a central image, word or phrase. From the central idea radiate the main themes of the subject as branches. The branches comprise of a keyword, image or topic presented on an associated line and they divide out into further higher-level sub branches. The branches usually diminish size and thickness meaning that they are thick at the center and finer towards the periphery. The small number of inner branches radiate out to a much larger number of outer branches. To aid the process of memory and recall, the mind map makes use of visual images where ever appropriate [29] which are helpful to illustrate different themes and topics. In addition, some different colors are used in order to differentiate areas of the mind map and help to divide different categories. The map represents the mental model of the team and it will represent the ideas of the group helping to create a big picture of everything the group wants to include. The mind map highlights the use of artistic and textual prompts to help with the organization of the ideas produced by the group. The main steps to follow in order to create a mind map are:

1. Start in the center of a blank page with a main idea to give freedom to spread in all directions in a free and natural way.

2. Use words, images or pictures for the central idea. A central image is however, more interesting and gives the brain more buzz.

3. Use colors in order to excite the brain because colors add extra vibrancy and life to the mind map and adds energy to the creative thinking process.

4. Connect the main branches to the central idea and connect the second and third level branches to the first and second levels. This procedure is useful because the brain works by association, linking things together. Connecting the branches helps to better understand and remember in an easiest way.

5. Make the branches curved in order to give the mind map more flexibility and use images throughout where considered appropriated.

\section{An ILlustration OF CONCEPT MAPPING AND Mind MAPPING IN CHEMICAL PRODUCT AND PROCESS DESIGN TEACHING}

Product and process design (PPD) is a curricular unit of the second semester of the chemical and biological engineering master course at ISEL a Portuguese engineering school in the Lisbon metropolitan area. Chemical product and process design is by no means of dough a creative exercise because the chemical engineer along with the development team must create new products using the tools he/she have been taught. Nevertheless, while teaching PPD we noticed that chemical engineering students do not see their engineering training as requiring much creativity and they experience some difficulties concerning product concept generation.

Due to their simplicity and flexibility we found interesting to teach the students how to use and explore some mapping methods as for example concept maps and mind maps. We felt that these maps had the potential to disclose students' thinking about a topic of interest and to reveal connections and inter relationships between the topics, being useful to stimulate the students' in order to generate and produce ideas through brainstorming, visualization and association of relationships, capturing the groups' thinking about a topic.

\section{A. An application of concept maps and mind maps in chemical product and process design teaching}

A problem was presented to the students to encourage the use of concept maps and mind maps. The problem considers the generation of ideas in order to improve a dry cleaning process.

When a garment has a "not for machine wash!" it has to be clean by a dry cleaning procedure. The dry cleaning is a process for textiles using a chemical solvent other than water. The most common solvent used is tetrachloroethylene usually identified in industry as "perc" from perchloroethylene. The process is used to clean delicate fabrics that cannot withstand the rough and tumble of a washing machine. This type of cleaning method produces hazardous waste, create air pollution and can lead to water and soil contamination.

This problem was given to chemical engineering students attending product and process design classes. in order to help the students to develop creative thinking skills and learn by an active learning process how to generate ideas and also how to map the generated ideas.

In order to understand the "dry cleaning process" the students built a concept map through the organization of knowledge. A characteristic of the concept map presented in Fig. 2 is that the concepts are represented in a hierarchical fashion with the most inclusive, most general concepts at the top of the map and the more specific less general concepts arranged hierarchically below. 


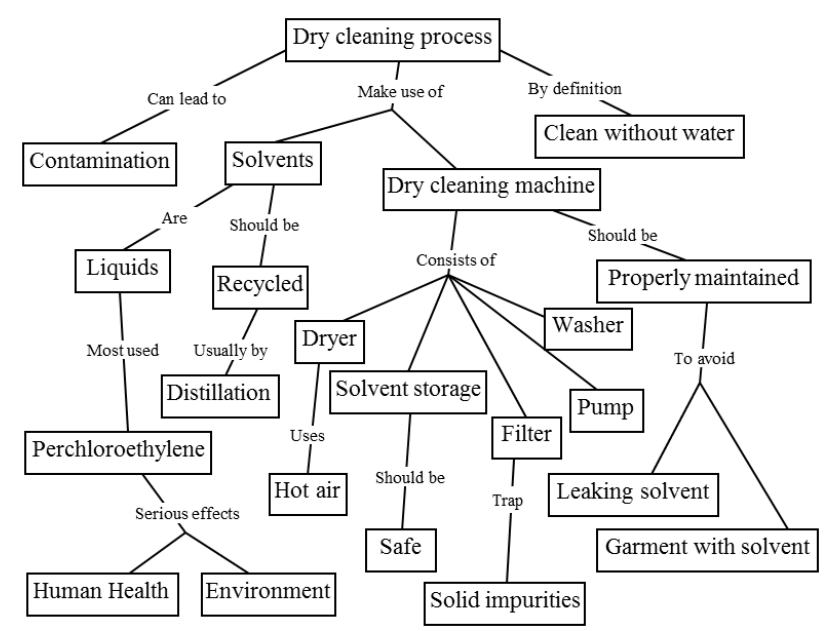

Figure 2. A sample of a concept map for a dry cleaning process

The hierarchical structure for a particular domain of knowledge depends on the context in which that knowledge is being applied or considered [32]. For example a concept map about the water cycle could be cyclic, while there is a still conceptual hierarchy of precedence or cause and effect in the concept map. Neither does it mean that concept maps need to have only one "root" concept. Yet, when learning to build concept maps, keeping the concept maps hierarchal with a single root makes it easier for the learner to grasp how concept maps are constructed [32].

A concept map of the "dry cleaning process" is a visual mode of presenting information making it easily comprehensible in a short time. The concept map allowed for a quick understanding of the process because of its conciseness and highlighting of key points. The map helped the group to understand the hierarchy and to understand how each component relates to the others. The map is read from the top down, beginning with the most general information and progressing to smaller detail. The map was useful for example to help to illustrate the group knowledge about the dry cleaning process reinforcing what the group already knew about the process and better understand and came out with ideas about what to be done to improve the dry cleaning process.

The use of concept mapping shows promise as a learning activity involving the students understanding of the concepts and the relationship among those concepts leading to higher order thinking [34].

In order to identify some ideas meant to improve the dry cleaning process the group started with the main topic and then in a freeway spread in several different directions. The mind map is presented in Fig. 3 with the main topic "improve dry cleaning process" as central topic. From this topic radiate the main ideas generated by the students as branches, divided into further higher level sub branches with increasing specificity. The students could experience that the representation promotes creativity and that one idea lead to another in a spontaneous free flowing manner.

There are some advantages of using mind maps to record the ideas and the information. If we compare mind mapping with linear methods of taking notes and record ideas, namely listing the ideas down the page, we can observe several advantages in using the mind mapping

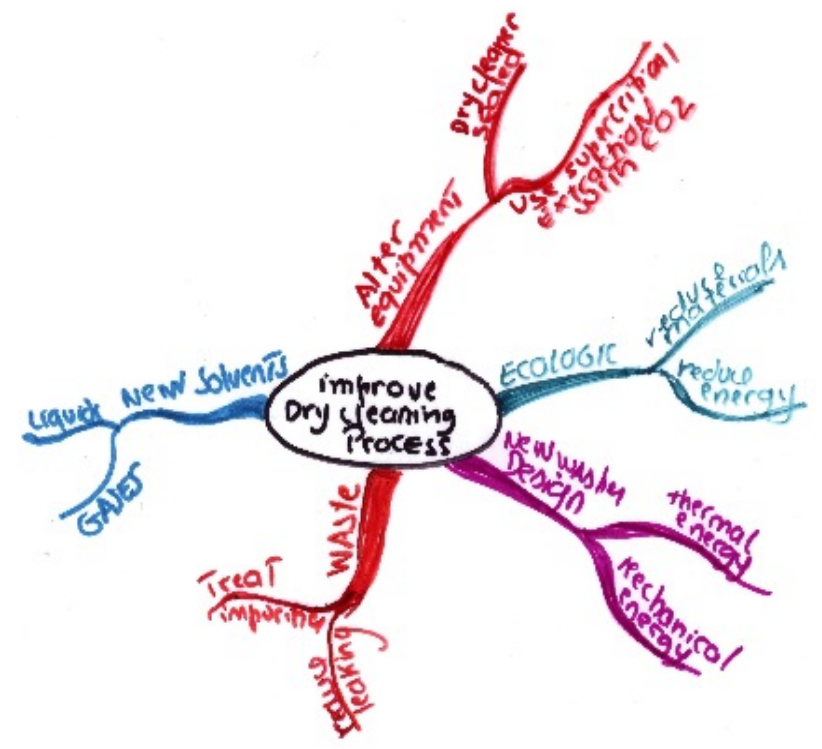

Figure 3. A sample of a mind map for a dry cleaning process

method. First mind maps allow adding new ideas in any direction and so it is a graphically useful form of brainstorming $[28,29]$. In addition, the map represents the way in which the brain works, and so it is possible to reach the mental model of the group allowing a large number of ideas to be compressed into a single page. The map is created in an organic and flexible way in which links can be created between all items and also the incorporation of colour and visual images will help the memorization process. Mind mapping allows for greater creativity when recording ideas and information and can be considered as a kind of divergent thinking [8].

The procedure for creating concept maps and mind maps can be applied in a traditional pen-and paper way or using a specific software tool. In this illustration the students built the maps as a first approach in a traditional pen and paper after a group post-it session. The students built and explained the maps in a three hour session.

\section{CONCLUSIONS}

Encourage creativity in chemical engineering curriculum address several concerns. First of all the design of large scale continuous plant is no longer what most engineers do and so an expanded design experience should prepare students for the more diverse and flexible roles they are now expected to perform in industry. Chemical product and process design is by no means of doubt a creative exercise and encouraging creativity allows to deal with ambiguous problems and help in the faster chemical product and process design resulting from time to market pressure always accompanied by an increasing demand for product differentiation.

Through the example concerning an illustrative case presented to chemical engineering students of product and process design course it was found that the use of maps is very helpful in order to change the usual thinking process and to stimulate creative thinking.

The visual representation is very helpful for generating ideas as well as graphically organizing and summarizing students' thoughts. These kinds of maps are very helpful to make students gradually build their thinking skills. 
Chemical engineering students are not used to be trained on idea generation methods but this type of methods are useful to stimulate creative thinking. Educational practices should give attention to creative problem solving skills. The teacher's role should be to stimulate and guide providing a favorable climate and the necessary tools. The student should discover what he learns, he should not just wait for the teacher to tell him/her the information [7].

When comparing the methods we can conclude that both methods, mind mapping and concept mapping, help to organize the existing knowledge and ideas. The mind map is very helpful in accelerating learning and the ability to remember and recall the information by surrounding the central idea by a radiant network of associated ideas. We start from a generic idea at the center, through an increased specificity at the outer extremes. By presenting the ideas with different colors and with visual stimulus, we help to trigger learning and understanding. The mind map is not inherently goal structured and so it is not action oriented but it helps to identify the factors associated with a topic but not necessarily focusing on outcomes. The concept map offers more flexibility in terms of expressing relationships between concepts. The concepts are presented as structures with one general broad idea at the top to the more specific at the bottom of the hierarchy, facilitating creative thinking [35]. In concept maps links are usually used to express any forms of relationships between concepts, identified by the group map builder.

It is worth to say that both methods are useful and both have benefits in order to stimulate the creative thinking. Using both methods in teaching is advantageous and provides benefits that go behind the use of each method alone. The students could see by active learning the potentialities of the mapping methods, and how helpful a graphical representation can be in the ideas generation step.

To conclude we believe that this type of maps are very useful to assist Chemical product design process raising the integration of teaching and learning chemical product and process design. The main objective will be to promote the development of thinking skills in future engineers to create new products through product and process design innovation and to improve existing products and processes efficiency.

\section{REFERENCES}

[1] E.L. Cussler and G.J. Wei, "Chemical product engineering," AIChE J., vol.49 (5), pp. 1072-1075, May 2003. http://dx.doi.org/10.1002/aic.690490502

[2] P.M. Saraiva and R. Costa,. "A chemical product design course with a quality focus," Trans IChemE, Part A, Chemical Engineering Research and Design, vol. 82 (A11), pp. 1474-1484, Novenber 2004.

[3] R. Costa, G.D. Moggridge and P.M. Saraiva, "Chemical product engineering: an emerging paradigm within chemical engineering," AIChE J., vol. 52 (6), pp. 1976-1986, June 2006. http://dx.doi.org/10.1002/aic.10880

[4] E. Favre, L. Marchal-Heusler and M. Kind, "Chemical product engineering: research and educational challenges," Trans IChemE, Part A, Chemical Engineering Research and Design, vol. 80 (A1), pp. 65-74, January 2002. http://dx.doi.org/10.1205/ 026387602753393231

[5] G.D. Moggridge and E.L Cussler, "An introduction to chemical product design," Trans IChemE, Part A, Chemical Engineering Research and Design, vol. 78 (A1), pp. 5-11, January 2000. http://dx.doi.org/10.1205/026387600527022
[6] K.L. Hohn, "Incorporating creativity into a capstone engineering design course," Proceedings of the 2010 Midwest Section Conference of the American Society for Engineering Education, pp. 1-7.

[7] J.P. Guilford, "Creativity research: Past, present and future," in Frontiers of creativity research, S. Isaksen Ed.. Buffalo, N.Y. Bearly Ltd., 1987, pp.33-66.

[8] G.J. Hwang, C.H. Wu, I. Huang and F.-R. Kuo, "A Mind Maporiented mobile learning approach to promoting creative thinking ability of students in a business course," Seventh IEEE International Conference on Wireless, Mobile and Ubiquitous Technology in Education, 2012, pp. 242-248.

[9] R. Shaheen, "Creativity and education," Creative Education, vol. 1(3), pp. 166-169, December 2010. http://dx.doi.org/10.4236/ ce. 2010.13026

[10] S.G. Bilén and R.F. Devon,"Innovative engineering design education," in ICED 05: 15th International Conference On Engineering Design: Engineering Design and the Global Economy, A. Samuel and W. Lewis, Eds., Barton, A.C.T.: Engineers Australia, 2005, pp. 3879-3888.

[11] K.-I. Vong, "Developing creativity and promoting social harmony: the relationship between government, school and parents' perceptions of children's creativity in Macau?SAR in China," Early Years: An International Journal of Research and Development, vol. 28(2), pp. 149-158, July 2008.

[12] E.L. Cussler and G.D. Moggridge, Chemical Product Design. Cambridge University Press, 2001.

[13] R.S. Nickerton. "Enhancing creativity", in Handbook of Creativity, R.J. Stemberg, Editor, Cambridge University Press, 1998, pp. 392-430.

[14] K. Adams, The sources of innovation and creativity. National Center on Education and the Economy, September 2005.

[15] H.B. Parkhurst, "Confusion, lack of consensus and the definition of creativity as a construct," Journal of Creative Behavior, vol.33, pp. 1-21 first quarter 1999.

[16] J.P. Guilford, "Creativity: yesterday, today e tomorrow", Journal of Creative Behavior, vol. 1, pp. 3-14, winter 1967.

[17] J. Baer, Creativity and divergent thinking: A task-specific approach, Hillsdale, NJ, England: Lawrence Erlbaum Associates, Inc., 1993.

[18] K. Otto and K. Wood, Product Desig. Techniques in Reverse Engineering and New Product Development, Prentice Hall, Inc., 2001.

[19] P. Bossche, W. Gijselaers, M. Segers, G. Woltjer and P. Kirschner, "Team learning: building shared mental models," Instr Sci, vol. 39 (3), pp. 283-301, May 2011. http://dx.doi.org/10.1007/ s11251-010-9128-3

[20] D. Ausubel, Educational Psychology: A Cognitive View. New York, Reinhart\&Winston, 1968.

[21] J.D. Novak, A theory of Education. Ithaca, N.Y.. Cornell University Press, 1977.

[22] D. Jonassen, T. Reeves, N. Hong, D. Harvey, and K. Peters, "Concept mapping as a cognitive learning and assessment tools,". Journal of Interactive Learning Research, vol. 8(3/4), pp. 289308, December 1997.

[23] D Jonassen, K. Beissner. and M. Yacci, Structural knowledge, New.York, Routledge, 1993

[24] J.D. Novak and D.B. Gowin, Learning How to Learn. New York: Cambridge University Press, 1984. http://dx.doi.org/10.1017/ CBO9781139173469

[25] D. Darmofal, D. Soderholm and D..Brodeur, "Using Concept Maps and Concept Qusetions to Enhance Conceptual Understanding," 32nd ASEE/IEEE Frontiers in Education Conference, Boston, MA, November 6 - 9, 2002, pp.1-7.

[26] W. Ibrahim, R. Morsi and T. Tuttle, "Concept Maps: An active learning and assessment tool in Electrical and Computer Engineering" in Illinois-Indiana and North Central Joint Section Conference of American Society for Engineering Education, Indiana University Purdue University Fort Wayne (IPFW), March 31April 1, 2006

[27] S. Muryanto, "Concept Mapping: "An Interesting and Useful Learning Tool for Chemical Engineering Laboratories," International Journal of Engineering Education, vol 22(5), , pp. 979-985, October 2006 , 
[28] T. Buzan, Use Your Head. Innovative Learning and Thinking Techniques to Fulfil Your Mental Potential. BBC books, 1974.

[29] T. Buzan, and B. Buzan, The Mind Map Book: How to Use Radiant Thinking to Maximize Your Brain's Untapped Potential. BBC books, 1993.

[30] J.D. Novak, "Concept maps and vee diagrams: Two metacognitive tools for science and mathematics education," Instructional Science, vol. 19, pp. 29-52, 1990. http://dx.doi.org/10.1007/ BF00377984

[31] J.D. Novak, "Clarify with concept maps," Science Teacher, vol. 58 (7), pp. 45-49, October 1991.

[32] J.D. Novak, and A.J. Canas, "The theory underlying concept maps and how to construct them," Technical Report IHMC CmapTools 2006-01 Rev 01-2008, Florida, Institute for Human and Machine Cognition, 2008, available at: http://cmap.ihmc.us/Publications/ResearchPapers/ TheoryUnderlyingConceptMaps.pdf

[33] P.S. Goel and N. Singh, "Creativity and innovation in durable product development," Computers \& Industrial Engineering vol. 35(1-2), pp. 5-8, October 1998. http://dx.doi.org/10.1016/S03608352(98)00006-0

[34] S.M. Zvacek, M.T. Restivo, M.F. Chouzal. "Concept mapping for higher order thinking." International Journal of Engineering Pedagogy, vol. 3, special issue 1, pp. 6-10, 2013.
[35] E. Mechlová and M. Malcik, "Testing concept maps electronically," $9^{\text {th }}$ International Conference on Emerging eLearning Technologies and Applications (ICETA), pp. 137-140, 27-28 October. 2011.

\section{AUTHORS}

I. M. João is with Chemical Engineering Department, Instituto Superior de Engenharia de Lisboa, Av. Conselheiro Emídio Navarro, 1959-007 Lisboa, Portugal (email:ijoao@deq.isel.ipl.pt) and with CEG-IST a research unit of Instituto Superior Técnico, Universidade de Lisboa Av. Rovisco Pais,1049-001, Lisboa, Portugal (email:isabel.joao@tecnico.ulisboa.pt)

J. M. Silva is with Chemical Engineering Department, Instituto Superior de Engenharia de Lisboa, Av. Conselheiro Emídio Navarro, 1959-007 Lisboa, Portugal (email: jmsilva@deq.isel.ipl.pt) and with CRERG-IBB a a research unit of Instituto Superior Técnico, Universidade de Lisboa Av. Rovisco Pais,1049-001, Lisboa, Portugal

This article is an extended and modified version of a paper presented at the CISPEE 2013 conference, held October 31 - November 01, 2013, in Porto, Portugal. Published 17 January 2014. Published as re-submitted by the author 07 March 2014. 